Шитова Ирина Юрьевна

канд. пед. наук, доцент

ГБОУ ВО «Крымский университет культуры, искусств и туризма»

г. Симферополь, Республика Крым

DOI $10.31483 / r-33337$

\title{
ТЕХНОЛОГИЯ «СМЕШАННОГО ОБУЧЕНИЯ»
}

\section{В ЗАРУБЕЖНЫХ ВУЗАХ: ПРЕИМУЩЕСТВА И НЕДОСТАТКИ}

Аннотация: рассмотрень модели смешанного обучения и виды деятельности, использующиеся в технологии смешанного обучения; охарактеризованы различие между взглядами студентов, преподавателей и руководителей университетов на преимущества смешанного обучения.

Ключевые слова: смечанное обучение, электронное обучение, комбинированное обучение.

Все сценарии обучения, которые не являются исключительно личным присутствием или интерактивным взаимодействием обучающихся, можно назвать смешанным обучением или гибридным обучением, то есть комбинацией интернет образовательных технологий, которые используются в качестве поддержки традиционного обучения.

Если различные уровни электронного обучения различаются в зависимости от степени их виртуализации, то смешанное обучение занимает промежуточное место между мультимедийными технологиями, сопровождающим процесс обучения в аудитории, и чистым онлайн-обучением.

Как традиционное обучение, предполагающее личное присутствие студентов на занятиях, так онлайн-мероприятия имеют специфические особенности. Например, студенты не всегда могут регулярно посещать лекционные и практические занятия, поэтому испытывают затруднения в устранении пробелов в знаниях. Проблемные области чистых онлайн-мероприятий включают в себя самоуправление и управление временем, а также отсутствие личного контакта (между студентами, а также между преподавателями и студентами). 
Технология смешанного обучения предоставляет студентам новые возможности по изучению дисциплин. Можно не только в любое время посмотреть необходимый материал в режиме онлайн, но пройти тестирование, проверить свои знания по предмету, ознакомиться с дополнительными источниками. Кроме того, в технологии смешанного обучения содержание учебного материала может быть представлено в аудио- и видеозаписи, анимации и симуляции, что в свою очередь позволяет студентам обращаться с учебной информацией достаточно гибко, в соответствии со своими потребностями и возможностями. События присутствия могут затем сосредоточиться на взаимодействии и обмене с другими студентами.

В смешанных сценариях обучения выделяют три вида деятельности [1]:

- самостоятельное электронное обучение: обучающиеся могут сами устанавливать время, интервалы, темп и место своей учебной деятельности («обучение в любое время и в любом месте»);

- электронное обучение в режиме реального времени: синхронные формы электронного обучения, например, лекции в виде веб-трансляции или работа в определенное время в виртуальном классе. Это позволяет обучающимся задавать вопросы преподавателям в режиме реального времени или взаимодействовать с другими студентами;

- традиционное преподавание в аудитории: лекции, семинары, упражнения, дискуссии и обмены проводятся в лекционном зале, лаборатории или комнате для семинаров и открывают личные контакты с преподавателями и сокурсниками.

Существуют разногласия по поводу того, каким образом в технологии «смешенного обучения» должно быть представлено соотношение аудиторных занятий и онлайн-обучения. Некоторые авторы считают, что процент контента онлайн-офлайн не так важен, как педагогический дизайн, а также сроки и последовательность действий, направленных на создание согласованного опыта обучения [4]. 
Выделяют четыре смешанные модели обучения, которые по-разному сочетают онлайн-обучение и традиционное обучение:

- модель ротации: курс состоит из заранее определенной структуры с присутствием и онлайн-акциями;

- гибкая модель: материалы предложения курса в основном доступны для студентов в Интернете. С преподавателями можно связаться по мере необходимости;

- самостоятельное «смешивание»: студенты выбирают изучение онлайнкурса, например, в другом университете (см. Предложения от Виртуального университета Баварии или Рурского кампуса онлайн) и тем самым дополняют свои курсы;

- обогащенная виртуальная модель: виртуальный курс, который включает в себя, например, предварительные предложения и предложения о наличии присутствия [3].

Кроме того, некоторые исследователи отмечают, что при смешанном обучении следует учитывать: сохранение традиционных, классических элементов, определяющих структуру процесса обучения; использование разнообразных форм учебной деятельности (разные формы индивидуальной и групповой работы); согласование целей обучения и приобретенных компетенций с конкретными методами [2, s. 117].

Основываясь на кратком изложении отчетов и тематических исследований разных университетов, выделены различия между взглядами студентов, преподавателей и руководителей университетов на преимущества смешанного обучения [8].

С точки зрения студентов, преимущества комбинированного обучения сопряжены с гибкостью занятий и получением практического опыта. Студенты, отдают первостепенное значение в виртуальной части обучения, возможности определить место и время обучения. Особенно отмечается возможность учиться, не выходя из дома. 
Для преподавателей смешанное обучение дает возможность изучить новые способы взаимодействия с участниками мероприятия. Например, когда студенты формируют онлайн-сообщество, лучше дискутируют и спорят на семинарах «лицом к лицу», углубляются в материал курса. Кроме того, как положительная характеристики технологии «смешанного обучения» преподавателями отмечается гибкость, вариативность проведения учебных занятий.

На уровне управления университетами ожидаются положительные результаты от сценариев смешанного обучения, начиная от позиционирования в качестве инновационного учебного заведения и заканчивая поиском новых целевых групп, особенно в области непрерывного профессионального образования, до более эффективного использования ресурсов и экономии затрат.

В качестве недостатков, использования смешанного обучения, можно отметить:

для студентов основные проблемы, связанные с курсами смешанного обучения, заключаются в ожидании того, что меньшее количество личных встреч также потребует меньше работы, дефицита времени и самоуправления, трудностей в принятии собственной ответственности за успех в обучении и технических проблем, особенно при работе с незнакомыми навыками общения, и инструменты сотрудничества.

Преподаватели нуждаются как в методической, так и в технической поддержке и помощи. Риски заключаются в потере контроля над учебной ситуацией и получение студентами, по завершение изучения учебного материала худшей оценки. Опыт также показывает, что событие, которое включает в себя онлайнкомпоненты, требует значительно больше времени для подготовки и проведения. Если мультимедийный контент должен быть разработан для конкретного учебного курса, то тогда потребуется еще больше дополнительного времени.

На уровне университетской организации использование технологий должно быть связано с общими и долгосрочными целями учреждения. Необходимо соответствующее распределение ресурсов и инвестиций в инфраструктуру и вспо- 
могательные подразделения. Также часто встречается сопротивление изменениям и инновациям. Преобразование структур учебных программ отнимает много времени и требует координации внутренних организационных процессов.

В качестве успешных примеров, иллюстрирующих использование технологии смешанного обучения в зарубежных вузах, можно отметить следующие:

Д-р Анжела Хоф в географическом институте Рурского университета в Бохуме использует технологию смешанного обучения при изучении студентами курса «Географические информационные системы в ландшафтной экологии». Электронные учебные материалы собственного производства, а также дополнительный электронный учебный контент были интегрированы в аудиторную работу. В рамках учебной проектной работы студенты могут получить углубленные методологические навыки, используя геоинформационные системы для решения сложных проблем экологии ландшафта.

Идея обучающего сценария, видео обучения практикуются на основе смешанного обучения в Институте коммуникационных технологий (факультет электротехники) в Ганноверском университете им. Лейбница [6].

Термин «перевернутая классная комната» относится к смешанной модели обучения. Лекции лектора для дальнейшей работы записаны до начала учебного курса и предоставлены студентам в режиме онлайн. О фактическом семинаре и дате лекции студентам не сообщается, но предоставляется возможность обсуждать вопросы и содержание лекции. Дополнительную информацию о модели и конференции по «перевернутая классная комната» в Германии и аналогичные примеры применения можно найти на странице «перевернутый класс» [5].

\section{Сиисок литературы}

1. Alonso F. An instructional model for web-based e-learning education with a blended learning process approach / F. Alonso, G. López, D. Manrique [et al.] // British Journal of Educational Technology. - 2007. - Vol. 36. - Issue 2. - P. 217-235.

2. Arnold P. Handbuch E-Learning - Lehren und Lernen mit digitalen Medien (2. erw., akt. u. vollst. überarb. Aufl.) / P. Arnold, L. Kilian, A. Thillosen [et al.]. - Bielefeld: W. Bertelsmann Verlag, 2011. 
3. Christensen C.M. Is K-12 Blended Learning Disruptive? An introduction to the theory of hybrids / C.M. Christensen, M.B. Horn, H. Staker. - 2013 [Электронный pecypc]. - Режим доступа: http://www.christenseninstitute.org/publications/hybrids/

4. Dziuban C.D. Higher education, blended learning, and the generations: Knowledge is power: No more: In J. Bourne \& J.C. Moore (Eds.), Elements of Quality Online Education: Engaging Communities / C.D. Dziuban, P.D. Moskal, J. Hartman. Needham: MA: Sloan Center for Online Education, 2005 [Электронный ресурс]. Режим доступа: http://desarrollodocente.uc.cl/images/Innovaci\%C3\%B3n/ Flipped/Knowledge_is_power_no_more.pdf

5. Inverted classroom [Электронный ресурс]. - Режим доступа: https://invertedclassroom.wordpress.com/

6. Krüger M. Selbstgesteuertes und kooperatives Lernen mit eLectures: Ein Widerspruch? [Электронный pecypc]. - Режим доступа: https://www.e-teaching.org/etresources/pdf/langtext_2010_krueger-marc_selbstgesteuertes-und-kooperatives-lernen-mit-electures.pdf

7. Nückles M. The use of public learning diaries in blended learning / M. Nückles, R. Schwonke, K. Berthold [et al.] // Journal of Educational Media. - 2004. - Vol. 29. №1. - P. 49-66 (18).

8. Vaughan N. Perspectives on Blended Learning in Higher Education // International Journal on E-Learning. - 2007. - №6 (1). - P. 81-94. - Chesapeake, VA: AACE. 